\title{
Efficient and Selective Iodination of Phenols Promoted by Iodine and Hydrogen Peroxide in Water
}

\author{
Rafael D. C. Gallo, Karimi S. Gebara, Rozanna M. Muzzi and Cristiano Raminelli* \\ Faculdade de Ciências Exatas e Tecnologia, Universidade Federal da Grande Dourados, \\ 79804-970 Dourados-MS, Brazil
}

\begin{abstract}
Uma reação simples e seletiva para a preparação de fenóis iodados foi desenvolvida e derivados fenólicos contendo substituintes eletroretiradores foram iodados em rendimentos muito bons sob condições relativamente brandas.
\end{abstract}

\begin{abstract}
A simple and selective reaction for the preparation of iodinated phenols was developed and phenol derivatives containing electron withdrawing groups were iodinated in very good yields
\end{abstract} under relatively mild conditions.

Keywords: reaction in water, iodination reaction, iodinated phenols

\section{Introduction}

In the course of our research envisioning the preparation of silylaryl triflates to produce arynes under mild reaction conditions, ${ }^{1}$ employing halophenols as starting materials, ${ }^{2}$ we came across a broad arsenal of methods for producing 2-iodophenols. ${ }^{3-5}$ On the other hand, when we idealized the preparation of 2,6-diiodophenols for the same purpose, we noted a lack of simple, efficient and selective procedures for the preparation of such compounds. ${ }^{3,5,6}$ Among the approaches to the synthesis of halogenated phenols, ${ }^{3-6}$ the electrophilic iodination using iodide or iodine in combination with an oxidizer has stood out. ${ }^{5}$ Independently of the synthetic methodology used to prepare the halophenols, they can be considered of great importance in synthetic organic chemistry, finding application, for example, in the preparation of 2-(trimethylsilyl)aryl triflates, which involves halophenol derivatives in metal-halogen exchange reations, ${ }^{1,2}$ and in the synthesis of oxygenated heterocyclic compounds via palladium-catalyzed transformations. ${ }^{7}$ 2-(Trimethylsilyl) aryl triflates are useful aryne precursors ${ }^{1,2}$ and oxygenated heterocyclic compounds are in some cases biologically active substances ${ }^{8}$ or natural products. ${ }^{9}$ Accordingly, having in mind our necessity for 2,6-diiodophenols, that are convenient starting materials in benzyne chemistry, along with the significant applicability of halophenols in

*e-mail: raminelli@ufgd.edu.br the preparation of heterocycles, we focused on development of a straightforward and highly selective methodology for the preparation of 2,6-diiodophenols, in order to obtain these compounds in good yields under mild reaction conditions, which include molecular iodine as the iodine source of choice, aqueous hydrogen peroxide as a safe and environmentally accepted oxidizer and water as a non flammable and innocuous solvent. In this work we disclose our findings concerning the synthesis of iodinated phenols using the already mentioned reaction conditions in full details.

\section{Results and Discussion}

In view of the convenient protocol reported by Jereb and co-authors for monoiodination of phenols using iodine and hydrogen peroxide, ${ }^{3}$ we decided to explore such reaction conditions aiming to the selective preparation of 2,6-diiodophenols in water (Table 1).

As can be seen in Table 1, allowing phenol (1a) to react with 0.5 equivalent of iodine and 1 equivalent of hydrogen peroxide in water at room temperature for $24 \mathrm{~h}$, 2,6-diiodophenol (2a) and 2-iodophenol (3) were isolated in yields of 21 and $49 \%$, respectively (entry 1, Table 1 ). In an attempt to prepare 2,6-diiodophenol (2a) in a better yield and with higher selectivity, subsequent work focused on optimization of these reaction conditions (Table 1). When the transformation was carried out using 0.75 equivalents of iodine and 1.5 equivalents of hydrogen peroxide, 
Table 1. Optimization of the synthesis of 2,6-diiodophenol (2a) ${ }^{\mathrm{a}}$

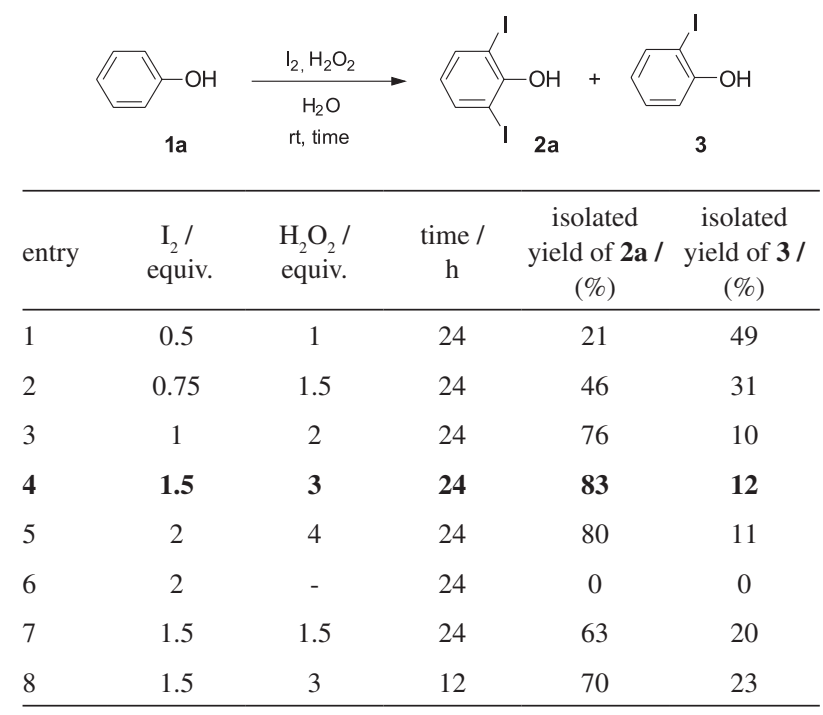

aReaction conditions: $2 \mathrm{mmol}$ of phenol (1a), the indicated amount of $\mathrm{I}_{2}$, the indicated amount of $\mathrm{H}_{2} \mathrm{O}_{2} 30 \%$, and $10 \mathrm{~mL}$ of $\mathrm{H}_{2} \mathrm{O}$ were stirred at room temperature for the time shown.

compound 2a was obtained in a moderate yield of $46 \%$, whereas compound $\mathbf{3}$ was isolated in a $31 \%$ yield (entry 2). By using 1 equivalent of iodine and 2 equivalents of hydrogen peroxide, 2,6-diiodophenol (2a) was prepared in a good yield of $76 \%$ and compound $\mathbf{3}$ in only $10 \%$ yield (entry 3). When we carried out the reaction employing 1.5 equivalents of iodine and 3 equivalents of hydrogen peroxide, 2,6-diiodophenol (2a) was isolated in an 83\% yield and 2-iodophenol was obtained in only $12 \%$ yield (entry 4). No significant improvement in the isolated yield of 2,6-diiodophenol (2a) and in the selectivity of the reaction were obtained when we allowed phenol (1a) to react with 2 equivalents of iodine and 4 equivalents of hydrogen peroxide in water at room temperature for 24 h (entry 5). As can be seen in Table 1, entry 6, both compounds 2a and $\mathbf{3}$ were not obtained and the starting material 1a was recovered when the reaction was carried out in the absence of hydrogen peroxide. This experiment shows that the success of our reaction depends dramatically on the presence of the oxidizer. Besides, the transformation was notably less selective when we decreased the amount of hydrogen peroxide or the reaction time (entries 7 and 8 , Table 1).

It is noteworthy the formation of ortho iodinated phenols (2a and $\mathbf{3}$ ) when phenol (1a) is allowed to react with iodine and hydrogen peroxide in water at room temperature (Table 1). However, the same selectivity has been observed for monoiodination of phenol using $\mathrm{I}_{2} / \mathrm{H}_{2} \mathrm{O}_{2} /$ $\mathrm{H}_{2} \mathrm{O} .{ }^{3}$ Presumably the species responsible for the iodination interacts with the phenolic hydroxyl group directing the attack to the ortho positions of the phenol (1a), leading to the production of 2,6-diiodophenol (2a) and 2-iodophenol (3). Although, 2,4-diiodophenol and 4-iodophenol were not produced, 2,4,6-triiodophenol was obtained in trace amount when the reaction was carried out using excess of iodine (entries 4 and 5, Table 1). In addition, when the reaction depicted in entry 4 , Table 1 , was performed at $50{ }^{\circ} \mathrm{C}, 2,4,6$-triiodophenol was produced in considerable amount according to the GC/MS analysis.

Afterwards, when we subjected 4-hydroxyacetophenone (1b) to the optimal conditions shown in Table 1, entry 4, we isolated 4-hydroxy-3,5-diiodoacetophenone (2b) in only $15 \%$ yield and 4-hydroxy-3-iodoacetophenone (4) in a $65 \%$ yield (Scheme 1).

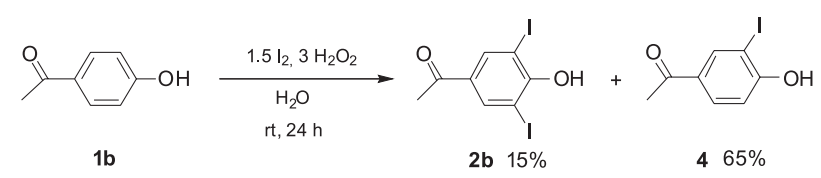

Scheme 1. Synthesis of iodinated hydroxyacetophenones $\mathbf{2 b}$ and $\mathbf{4}$.

In the attempt to prepare $\mathbf{2} \mathbf{b}$ as the major product, we performed the reaction depicted in Scheme 1 at $50{ }^{\circ} \mathrm{C}$ and isolated the compound $\mathbf{2 b}$ in a $92 \%$ yield (entry 2 , Table 2). In this slightly higher temperature iodophenols bearing electron withdrawing substituents were produced in excellent yields (Table 2).

In order to examine the scope and limitations of the process, allowing 4-nitrophenol (1c) to react with 1.5 equivalents of iodine and 3 equivalents of hydrogen peroxide in water at $50{ }^{\circ} \mathrm{C}$ for $24 \mathrm{~h}, 2,6$-diiodo-4-nitrophenol (2c) was obtained in a very good yield of $80 \%$ (entry 3 , Table 2). When 4-chlorophenol (1d) was subjected to the iodination reaction using the same conditions, 4-chloro2,6-diiodophenol (2d) was isolated in an excellent 93\% yield (entry 4). By using 2-bromophenol (1e), which is blocked at the 2-position with an electron withdrawing substituent, we obtained 2-bromo-4,6-diiodophenol (2e) in a $90 \%$ yield (entry 5). Accordingly, the reaction between 2,6-dichlorophenol (1f) and iodine in the presence of hydrogen peroxide gave 2,6-dichloro-4-iodophenol (2f) in a 95\% yield (entry 6). The treatment of 4-methoxyphenol (1g) with iodine and hydrogen peroxide in water did not lead to the formation of the desired product $2 \mathrm{~g}$ (entry 7). In this reaction the starting material was completely consumed and a mixture of non identified substances was produced. The transformation shown in Table 2, entry 7 , was also performed at room temperature to give roughly the same results. No attempts were made to optimize this reaction.

The structures of compounds $\mathbf{2 a - f}, \mathbf{3}$ and $\mathbf{4}$ have been assigned on the basis of a variety of spectroscopic techniques, namely, according to their LRMS, IR, ${ }^{1} \mathrm{H}$, and ${ }^{13} \mathrm{C}$ NMR 
Table 2. Synthesis of iodophenols (2) by the reaction of phenols (1) with iodine in the presence of hydrogen peroxide using water as solvent ${ }^{\mathrm{a}}$

(isolated

aReaction conditions: $2 \mathrm{mmol}$ of phenol (1), $3 \mathrm{mmol}$ of $\mathrm{I}_{2}, 6 \mathrm{mmol}$ of $\mathrm{H}_{2} \mathrm{O}_{2}$ $30 \%$, and $10 \mathrm{~mL}$ of $\mathrm{H}_{2} \mathrm{O}$ were stirred at $50{ }^{\circ} \mathrm{C}$ for $24 \mathrm{~h}$. ${ }^{\mathrm{b}}$ This reaction was carried out at room temperature for $24 \mathrm{~h}$. ${ }^{\circ}$ The compound $2 \mathrm{~g}$ was not obtained when the reaction was carried out at $50^{\circ} \mathrm{C}$ for $24 \mathrm{~h}$ nor when the reaction was carried out at room temperature for $24 \mathrm{~h}$.

spectra. All substances produced (2a-f, 3 and $\mathbf{4}$ ) were previously synthesized by other synthetic methodologies and provided melting point values and spectral data which are in accordance with those already published.

\section{Conclusions}

In summary, a simple, efficient and selective reaction for the preparation of iodophenols was developed and phenol derivatives containing electron withdrawing groups were iodinated in very good yields under relatively mild conditions which include the use of water as solvent.

\section{Experimental}

\section{General methods}

${ }^{1} \mathrm{H}$ and ${ }^{13} \mathrm{C}$ NMR spectra were obtained on a Varian INOVA 300 spectrometer $\left({ }^{1} \mathrm{H}\right.$ at $300 \mathrm{MHz}$ and ${ }^{13} \mathrm{C}$ at
$75 \mathrm{MHz})$ and on a Bruker DRX-500 spectrometer $\left({ }^{1} \mathrm{H}\right.$ at $500 \mathrm{MHz}$ and ${ }^{13} \mathrm{C}$ at $125 \mathrm{MHz}$ ). The spectra were taken in deuterated solvents and the chemical shifts were given in ppm using residual undeuterated solvents or tetramethylsilane (TMS) as internal standard. Low-resolution mass spectra were obtained on a Shimadzu CG-17A/CGMS-QP5050A instrument. Near-IR spectra were obtained on a Bomem MB-100 spectrometer. All melting point values are uncorrected. All reagents and solvents were used as obtained commercially. Column chromatography separations were carried out using 70-230 mesh silica gel 60 .

\section{General procedure}

To a solution of the appropriate phenol (1a-g) $(2 \mathrm{mmol})$ and iodine $(0.7620 \mathrm{~g}, 3 \mathrm{mmol})$ in distilled water $(10 \mathrm{~mL})$ was added hydrogen peroxide $(0.68 \mathrm{~mL}$ of a $30 \%(\mathrm{~m} / \mathrm{v})$ aqueous solution, $6 \mathrm{mmol}$ ). The mixture was stirred at room temperature or at $50{ }^{\circ} \mathrm{C}$ for $24 \mathrm{~h}$. Afterwards, a $10 \%(\mathrm{~m} / \mathrm{v})$ sodium thiosulfate aqueous solution $(10 \mathrm{~mL})$ was added to the mixture, which was extracted with dichloromethane or ethyl acetate $(3 \times 20 \mathrm{~mL})$. The organic phase was dried over $\mathrm{MgSO}_{4}$. After filtration, the solvent was evaporated under reduced pressure. The residue was purified by column chromatography on silica gel using a mixture of hexane/ dichloromethane (1/1) unless otherwise indicated, affording the desired product (2a-f, $\mathbf{3}$ and $\mathbf{4}$ ).

\section{2,6-Diiodophenol (2a) (CAS number: 28177-54-0)}

Yield $0.5744 \mathrm{~g}(83 \%)$; off-white solid; $\mathrm{mp} 64-65{ }^{\circ} \mathrm{C}$ (lit. $\left.{ }^{10} \mathrm{mp} 66-67{ }^{\circ} \mathrm{C}\right) ; 500 \mathrm{MHz}{ }^{1} \mathrm{H} \mathrm{NMR}\left(\mathrm{CDCl}_{3}\right): \delta 7.67$ (d, $J 8.0 \mathrm{~Hz}, 2 \mathrm{H}), 6.39(\mathrm{t}, J 8.0 \mathrm{~Hz}, 1 \mathrm{H}), 5.75(\mathrm{~s}, 1 \mathrm{H}) ; 125 \mathrm{MHz}$ ${ }^{13} \mathrm{C}$ NMR $\left(\mathrm{CDCl}_{3}\right): 153.4,139.2,124.1,82.5$; IR (KBr) $v_{\max } / \mathrm{cm}^{-1}: 3463,1433,1313,1235,752,687$; LRMS (m/z, \%): 346 (100.0), 219 (2.3), 127 (9.6), 92 (74.3).

\section{2-Iodophenol (3) (CAS number: 533-58-4)}

Yield $0.2156 \mathrm{~g}(49 \%)$; brownish solid; $\mathrm{mp} 40-42{ }^{\circ} \mathrm{C}$ (lit. $\left.{ }^{10} \mathrm{mp} 43-44{ }^{\circ} \mathrm{C}\right) ; 300 \mathrm{MHz}{ }^{1} \mathrm{H}$ NMR $\left(\mathrm{CDCl}_{3}\right): \delta 7.65$ (dd, $J 8.1,1.5 \mathrm{~Hz}, 1 \mathrm{H}), 7.23(\mathrm{ddd}, J 8.1,7.5,1.5 \mathrm{~Hz}, 1 \mathrm{H})$, 6.99 (dd, $J 8.1,1.5 \mathrm{~Hz}, 1 \mathrm{H}), 6.66$ (ddd, $J 8.1,7.4,1.5 \mathrm{~Hz}$, $1 \mathrm{H}), 5.36(\mathrm{~s}, 1 \mathrm{H}) ; 75 \mathrm{MHz}^{13} \mathrm{C} \mathrm{NMR}\left(\mathrm{CDCl}_{3}\right): 154.7,138.3$, 130.2, 122.4, 115.1, 85.7; IR (KBr) $v_{\max } / \mathrm{cm}^{-1}: 3476,1467$, 1443, 1192, 1178, 1016, 750; LRMS ( $/ \mathrm{z}, \%$ ): 220 (100.0), 127 (2.3), 93 (2.2), 65 (15.0).

\section{4-Hydroxy-3,5-diiodoacetophenone (2b) (CAS number: 7191-55-1)}

The eluent used was dichloromethane; yield $0.7139 \mathrm{~g}$ (92\%); off-white solid; mp $175-177^{\circ} \mathrm{C}$ (lit. ${ }^{11} \mathrm{mp} 173{ }^{\circ} \mathrm{C}$ ); $500 \mathrm{MHz}{ }^{1} \mathrm{H}$ NMR (DMSO- $d_{6}$ ): $\delta 10.38$ (s, $1 \mathrm{H}$ ), 8.25 (s, 
2H), 2.50 (s, 3H); $125 \mathrm{MHz}{ }^{13} \mathrm{C}$ NMR (DMSO- $d_{6}$ ): $\delta 194.3$, 159.4, 139.4, 132.5, 86.0, 26.3; IR (KBr) $v_{\max } / \mathrm{cm}^{-1}: 3141$, 1666, 1525, 1355, 1233, 1121, 1070; LRMS $(\mathrm{m} / \mathrm{z}, \%): 388$ (72.8), 373 (100.0), 345 (9.3), 127 (1.4).

4-Hydroxy-3-iodoacetophenone (4) (CAS number: 6261524-1)

The eluent used was dichloromethane; yield $0.3406 \mathrm{~g}$ (65\%); off-white solid; mp $156-158{ }^{\circ} \mathrm{C}$ (lit. ${ }^{12} \mathrm{mp}$ 153-155 ${ }^{\circ} \mathrm{C}$ ); $500 \mathrm{MHz}{ }^{1} \mathrm{H}$ NMR (DMSO- $d_{6}$ ): $\delta 11.25$ (s, $1 \mathrm{H}), 8.24(\mathrm{~d}, J 2.0 \mathrm{~Hz}, 1 \mathrm{H}), 7.83(\mathrm{dd}, J 8.5,1.5 \mathrm{~Hz}, 1 \mathrm{H})$, 6.95 (d, $J 8.5 \mathrm{~Hz}, 1 \mathrm{H}), 2.48$ (s, 3H); $125 \mathrm{MHz}{ }^{13} \mathrm{C}$ NMR (DMSO- $\left.d_{6}\right): \delta$ 195.0, 160.9, 139.4, 130.3, 130.2, 114.4, 84.6, 26.2; IR (KBr) $v_{\max } / \mathrm{cm}^{-1}: 3187,1651,1592,1357$, 1288, 1268, 825; LRMS ( $\mathrm{m} / \mathrm{z}, \%): 262$ (48.4), 247 (100.0), 219 (11.1), 127 (1.4).

2,6-Diiodo-4-nitrophenol (2c) (CAS number: 305-85-1)

Yield $0.6256 \mathrm{~g}(80 \%)$; yellowish solid; $\mathrm{mp} 157-158^{\circ} \mathrm{C}$ (lit. ${ }^{13} \mathrm{mp} 155-156^{\circ} \mathrm{C}$ ); $300 \mathrm{MHz}{ }^{1} \mathrm{H}$ NMR ( $\mathrm{CD}_{3} \mathrm{OD}$ ): $\delta 8.57$ (s, 2H); $75 \mathrm{MHz}^{13} \mathrm{C}$ NMR (CD $\left.\mathrm{OD}\right): \delta 163.1,143.0,136.2$, 83.1; IR (KBr) $v_{\text {max }} / \mathrm{cm}^{-1}: 3375,3077,1504,1399,1317$, 1230, 1116; LRMS (m/z, \%): 391 (100.0), 345 (8.1), 218 (16.9), 127 (18.6).

4-Chloro-2,6-diiodophenol (2d) (CAS number: 1545950-4)

Yield $0.7220 \mathrm{~g}(95 \%)$; off-white solid; $\mathrm{mp} 104-106^{\circ} \mathrm{C}$ (lit. $\left.{ }^{14} \mathrm{mp} 107-108^{\circ} \mathrm{C}\right) ; 300 \mathrm{MHz}{ }^{1} \mathrm{H}$ NMR $\left(\mathrm{CDCl}_{3}\right): \delta 7.66$ (s, 2H), 5.71 (s, $1 \mathrm{H}) ; 75 \mathrm{MHz}{ }^{13} \mathrm{C} \mathrm{NMR}\left(\mathrm{CDCl}_{3}\right): 152.7$, 138.2, 126.7, 81.7; IR (KBr) $v_{\max } / \mathrm{cm}^{-1}: 3455,3068,1440$, 1306, 1145, 857, 700; LRMS ( $\mathrm{m} / \mathrm{z}, \%): 380$ (100.0), 382 (34.4), 253 (2.8), 255 (0.9), 126 (20.9), 127 (12.8), 128 (7.7).

2-Bromo-4,6-diiodophenol (2e) (CAS number: 89466-01-3) Yield $0.7650 \mathrm{~g}(90 \%)$; off-white solid; $\mathrm{mp} 125-127^{\circ} \mathrm{C}$ (lit. ${ }^{15} \mathrm{mp} 128^{\circ} \mathrm{C}$ ); $300 \mathrm{MHz}{ }^{1} \mathrm{H}$ NMR (DMSO- $d_{6}$ ): $\delta 10.07$ (s, 1H), $7.98(\mathrm{~d}, J 2.0 \mathrm{~Hz}, 1 \mathrm{H}), 7.83(\mathrm{~d}, J 2.0 \mathrm{~Hz}, 1 \mathrm{H}) ; 75$ $\mathrm{MHz}{ }^{13} \mathrm{C}$ NMR (DMSO- $d_{6}$ ): 153.2, 145.1, 140.1, 111.5, 90.0, 83.8; IR (KBr) $v_{\text {max }} / \mathrm{cm}^{-1}: 3446,3060,1441,1372$, 1231, 1143, 857; LRMS ( $\mathrm{m} / \mathrm{z}, \%)$ : 426 (100.0), 424 (98.0), 299 (11.9), 297 (12.8), 172 (18.6), 170 (19.1), 127 (9.9).

\section{2,6-Dichloro-4-iodophenol (2f) (CAS number: 34074-22-1)}

Yield $0.5491 \mathrm{~g}(95 \%)$; off-white solid; $\mathrm{mp} 90-91{ }^{\circ} \mathrm{C}$ (lit. ${ }^{16} \mathrm{mp} 91-92{ }^{\circ} \mathrm{C}$ ); $300 \mathrm{MHz}{ }^{1} \mathrm{H}$ NMR (DMSO- $d_{6}$ ): $\delta$ 10.42 (s, $1 \mathrm{H}$ ), 7.67 (s, 2H); $75 \mathrm{MHz}{ }^{13} \mathrm{C}$ NMR (DMSO- $d_{6}$ ): 149.8, 136.7, 124.0, 81.4; IR (KBr) $v_{\max } / \mathrm{cm}^{-1}: 3378,3065$, 1468, 1457, 1384, 1236, 855; LRMS ( $\mathrm{m} / \mathrm{z}, \%)$ : 288 (100.0), 290 (63.1), 292 (10.7), 161 (17.9), 163 (11.6), 165 (2.1).

\section{Acknowledgments}

We gratefully acknowledge the Conselho Nacional de Desenvolvimento Científico e Tecnológico-CNPq (Brazil) for financial support.

\section{References}

1. Liu, Z.; Shi, F.; Martinez, P. G. D.; Raminelli, C.; Larock, R. C.; J. Org. Chem. 2008, 73, 219; Toledo, F. T.; Marques, H.; Comasseto, J. V.; Raminelli, C.; Tetrahedron Lett. 2007, 48, 8125; Raminelli, C.; Liu, Z.; Larock, R. C.; J. Org. Chem. 2006, $71,4689$.

2. Peña, D.; Cobas, A.; Pérez, D.; Guitián, E.; Synthesis 2002, 1454; Himeshima, Y.; Sonoda, T.; Kobayashi, H.; Chem. Lett. 1983, 1211.

3. Jereb, M.; Zupan, M.; Stavber, S.; Chem. Commun. 2004, 2614.

4. Das, B.; Krishnaiah, M.; Venkateswarlu, K; Reddy, V. S; Tetrahedron Lett. 2007, 48, 81; Ganta, A.; Snowden, T. S.; Synlett 2007, 2227; Sathiyapriya, R.; Karunakaran, R. J.; Synth. Commun. 2006, 36, 1915; de Rege, F. M. G.; Buchwald, S. L.; Tetrahedron 1995, 51, 4291; Whitmore, F. C.; Hanson, E. R. In Organic Syntheses; Kamm, O., ed.; John Wiley \& Sons: New York, 1941; Coll. Vol. 1, pp. 326.

5. Stavber, S.; Jereb, M.; Zupan, M.; Synthesis 2008, 1487.

6. Ribeiro, R. da S.; Esteves, P. M.; de Mattos, M. C. S.; J. Braz. Chem. Soc. 2008, 19, 1239; Kiran, Y. B.; Konakahara, T.; Sakai, N.; Synthesis 2008, 2327; Lista, L.; Pezzella, A.; Napolitano, A.; d’Ischia, M.; Tetrahedron 2008, 64, 234; Kauch, M.; Hoppe, D.; Synthesis 2006, 1578; Iskra, J.; Stavber, S.; Zupan, M.; Synthesis 2004, 1869; Adimurthy, S.; Ramachandraiah, G.; Ghosh, P. K.; Bedekar, A. V.; Tetrahedron Lett. 2003, 44, 5099.

7. Zeni, G.; Larock, R. C.; Chem. Rev. 2006, 106, 4644; Zeni, G.; Larock, R. C.; Chem. Rev. 2004, 104, 2285; Kundu, N. G.; Pal, M.; Mahanty, J. S.; De, M.; J. Chem. Soc., Perkin Trans. 1 1997, 2815; Larock, R. C.; Yum, E. K.; Doty, M. J.; Sham, K. K. C.; J. Org. Chem. 1995, 60, 3270; Larock, R. C.; Berrios-Peña, N. G.; Fried, C. A.; Yum, E. K.; Tu, C.; Leong, W.; J. Org. Chem. 1993, 58, 4509.

8. Bakunov, S. A.; Bakunova, S. M.; Bridges, A. S.; Wenzler, T.; Barszcz, T.; Werbovetz, K. A.; Brun, R.; Tidwell, R. R.; J. Med. Chem. 2009, 52, 5763; Dixit, M.; Tripathi, B. K.; Tamrakar, A. K.; Srivastava, A. K.; Kumar, B.; Goel A.; Bioorg. Med. Chem. 2007, 15, 727; Khan, M. W.; Alam, M. J.; Rashid, M. A.; Crowdhury, R.; Bioorg. Med. Chem. 2005, 13, 4796.

9. Dat, N. T.; Jin, X.; Lee, K.; Hong, Y.-S.; Kim, Y. H.; Lee, J. J.; J. Nat. Prod. 2009, 72, 39; Kapche, G. D. W. F.; Fozing, C. D.; Donfack, J. H.; Fotso, G. W.; Amadou, D.; Tchana, A. N.; Bezabih, M.; Moundipa, P. F.; Ngadjui, B. T.; Phytochemistry 2009, 70, 216; Huang, H.-Y.; Ishikawa, T.; Peng, C.-F.; Tsai, I.-L.; Chen, I.-S.; J. Nat. Prod. 2008, 71, 1146. 
10. Horiuchi, C. A.; Satoh, J. Y.; Bull. Chem. Soc. Jpn. 1984, 57, 2691.

11. Baker, W.; Sansbury, H.; Simmonds, W. H. C.; J. Soc. Chem. Ind. 1943, 62, 193.

12. Zenner, J. M.; Larock, R. C.; J. Org. Chem. 1999, 64, 7312.

13. Sapountzis, I.; Dube, H.; Lewis, R.; Gommermann, N.; Knochel, P.; J. Org. Chem. 2005, 70, 2445.
14. Hunter, W. H.; Joyce, F. E.; J. Am. Chem. Soc. 1917, 39, 2640.

15. Brenans, P.; Yeu, K.; Compt. Rend. 1930, 190, 1560.

16. Brazier, S. A.; McCombie, H.; J. Chem. Soc., Trans. 1912, 101, 968.

Received: August 7, 2009

Web Release Date: December 15, 2009 